\title{
Undergraduate Nursing Students' Challenges when Writing Research Proposals at the University of Namibia
}

\author{
Daniel Opotamutale Ashipala \\ https://orcid.org/0000-0002-8913-056X \\ University of Namibia \\ dashipala@unam.na
}

\author{
Rebecca Musore Livingi \\ https://orcid.org/0000-0002-8804-183X \\ University of Namibia \\ rebbalivingi@gmail.com
}

\section{Abstract}

Research topic selection and problem formulation are prerequisites when preparing a proposal for conducting research. However, nursing students find this a daunting task when doing it for the first time, despite the research methodology module that introduces nursing students to research. Institutions of higher learning should, therefore, establish the challenges that undergraduate nursing students face when writing their research proposals to develop strategies in order to mitigate these challenges. In Namibia, students' challenges when writing research proposals have not been extensively researched. This study aimed to explore and describe undergraduate nursing students' challenges when writing research proposals at the University of Namibia (UNAM), with a view to describing the factors that affect this. Accordingly, a qualitative, explorative, descriptive and contextual design was applied and purposive sampling was used to select 20 undergraduate nursing students enrolled for the Bachelor of Nursing Science (Clinical) (Honours) at UNAM. Individual interviews were conducted, using semi-structured interviews in line with an interview guide. Data were analysed by means of qualitative thematic analysis, which identified the following themes: challenging experiences when writing the research proposal; influence of the supervisor; and recommendations for improvement. The findings of this study call for well-articulated plans and actions from the lecturers and supervisors involved to address the challenges highlighted in this study, as well as actions and plans that should inform the curriculum. A need was identified for a strong focus on library information literacy and English for academic writing to be taught simultaneously with the writing of research proposals from the third year.

\section{UNISA $\approx$}




\section{Ashipala, Livingi}

Keywords: challenges; experiences; undergraduate nursing students; research proposals; students; research; University of Namibia

\section{Introduction}

As part of the fulfilment of their degrees, undergraduate students are required to carry out research. In tertiary education institutions worldwide, a research proposal is a fundamental part of the thesis production process and, without a clear proposal, it is unlikely that students will be able to embark on a systematic investigation or discussion of a problematic issue within their area of research (Botten 2012). Researchers generally face many challenges during the research process, both globally and at the University of Namibia (UNAM), where this study was conducted; and nursing students are no exception.

The goal of a research proposal is to present and justify a research idea and to present practical ways in which one thinks the research should be conducted. It should contain an extensive literature review and should provide persuasive evidence that there is a need for the research being proposed (Mapolisa and Mafa 2012). In addition to providing a rationale for the proposed research, a proposal describes a detailed methodology for conducting the research consistent with the requirements of the professional or academic field, as well as the anticipated outcomes and/or benefits derived from the study. According to Anderson and Krathwohl (2015), a proposal should contain all the key elements involved in designing a complete research study, with sufficient information to allow readers to assess its validity and usefulness. The only elements missing from a research proposal are the results of the study and the analysis of those results.

Additionally, Paul (2015) notes that a researcher's research is only as good as their proposal and that a wrongly prepared proposal dooms the research project to failure. By contrast, one that has been well designed promises success and a good impression to supervisors. For this reason, Paul (2015) argues that a research proposal should convince others that the topic is worthy of researching and that the researcher will be able to carry out the research competently.

A study conducted in Tanzania on research proposal writing, found that most studies conducted worldwide on undergraduate training have focused on issues of supervision (Hartley and Jory 2015; Mafa and Mapolisa 2011; Murray 2012; Taylor and Beasley 2015). The limited studies on the challenges of writing theses or dissertations (Bitchener and Basturkmen 2006; Lessing and Schulze 2002; Wang and Li 2008) have focused on international students pursuing their studies in either the United Kingdom or elsewhere, outside the African continent. Therefore, this study was triggered by the limited knowledge on the nature and scope of the challenges facing the majority of undergraduate students in the Tanzanian context when writing theses and dissertations (Komba 2016). The study was timely, as the findings were envisaged to inform both students and academic staff in Tanzanian higher learning institutions about the issues 


\section{Ashipala, Livingi}

related to thesis and dissertation writing. Specifically, the findings were expected to serve as baseline information for making recommendations on how best the challenges facing postgraduate students when writing theses and dissertations, could be overcome. This study thus serves as a basis for exploring the challenges undergraduate nursing students experience when writing research proposals at UNAM.

\section{Statement of the Research Problem}

One of the requirements for obtaining an undergraduate degree is to conduct research. This provides an avenue for students to gain in-depth experiential learning by conducting research on a topic related to their specific field of study. Undergraduate research also provides an opportunity for research supervisors to guide students on their path to becoming professionals and it helps them to explore career opportunities that they may not otherwise be aware of (Asogwa, Wombo, and Ugwuoke 2014).

Writing a research proposal to conduct research (for the first time) is a daunting task, despite numerous modules that introduce research to undergraduate nursing students. The literature documents many factors that influence this activity, including students' under-preparedness (Asogwa et al. 2014; Nkomo 2013) and (Govender and Ramroop 2013). At UNAM, proposal writing is an academic activity that takes place in undergraduate nursing students' third year, while writing up the project takes place in the fourth (final) year of Bachelor of Nursing Science (Clinical) (Honours) training. The fourth-year level has been elevated to National Qualification Framework (NQF) level 8 and, therefore, has to align with the level as envisaged by the Namibian Qualifications Authority (NQA 2014).

Over the years, the researchers in the current study have observed that third-year undergraduate nursing students at UNAM struggle to write their research proposals to the extent that their research study may be delayed or, at worst, may result in them not graduating on time. In some extreme cases, this leads to some of the students withdrawing from their studies because they have not completed the dissertation required to obtain their intended degrees, even when they have passed their coursework creditably (Asogwa et al. 2014). Consequently, some undergraduate students do not complete their research within the timeframe allocated, often leading to their withdrawal from their studies.

\section{Research Questions}

The following research questions were posed:

- What challenges do undergraduate nursing students face when writing their research proposals at UNAM?

- What recommendations could be made to address the challenges students are facing when writing their research proposals at UNAM? 


\section{Purpose of the Study}

The purpose of the study was to explore and describe undergraduate nursing students' challenges when writing research proposals at UNAM.

\section{Objectives of the Study}

The following objectives were formulated:

- To explore undergraduate nursing students' challenges when writing research proposals at UNAM.

- To describe undergraduate nursing students' challenges when writing research proposals at UNAM.

- To make recommendations to address the challenges students are facing when writing their research proposals at UNAM.

\section{Definition of Key Concepts}

\section{Research Proposal}

A research proposal is a written statement or plan of the research design which must be submitted to gain approval for the study and the data collection process to follow (Brink, Van der Walt, and Van Rensburg 2018). In this study, "research proposal" refers to a concise and coherent summary of the proposed research study, which sets out the central issues or questions that a researcher wishes to address.

\section{Undergraduate Nursing Students}

An undergraduate nursing student is a person who is formally engaged in learning and who is enrolled for a first professional diploma/degree at a higher education institution (Oxford Dictionary 2019). In the context of this study, an undergraduate nursing student refers to a student who is enrolled fulltime in the School of Nursing Science at UNAM for a Bachelor of Nursing Science (Clinical) (Honours) offered in line with the Namibia Qualifications Framework Level 8.

\section{Challenges}

According to the Oxford Dictionary (2019), a challenge is a situation involving being faced with something that needs great mental or physical effort in order to be done successfully and, therefore, tests a person's ability. In this study, "challenges" refer to something new, which in this case is writing a research proposal, that seems difficult and requires great effort and determination from students in order for them to succeed in the tertiary institutions. 


\section{Methodology}

\section{Research Design}

The study used an explorative, descriptive and contextual research design in the qualitative research tradition to explore the meaning of the experiences of undergraduate nursing students as described by them individually. Qualitative research is concerned with everyday human experiences in a natural environment (Maree 2016). The semi-structured individual interviews conducted have enabled the researcher to understand the experiences of the participants.

\section{Research Method}

The study used semi-structured interviews that focused on exploring the experiences of undergraduate Bachelor of Nursing Science (Clinical) (Honours) students as they occurred. These interviews were facilitated through the use of open-ended questions which oriented the study. Asking such questions allows a researcher to gain a better understanding of the scope of the research topic.

\section{Study Population}

Grove, Burns, and Gray (2013) define a study population as the bigger pool from which sample elements are drawn. The accessible population in this study consisted of 20 undergraduate third year nursing students enrolled for the Bachelor of Nursing Science (Clinical) (Honours) at the UNAM School of Nursing at Rundu campus in 2020.

\section{Sample and Sampling Technique}

In the research context, a sample is a subset of the population elements (Polit and Beck 2012). The sample for the current study comprised students enrolled for the Bachelor of Nursing Science (Clinical) (Honours) at the UNAM School of Nursing in Rundu in 2020. Purposeful sampling was employed, which was based on the judgement of the researcher regarding participants whom the researcher felt would be especially knowledgeable about the research topic.

\section{Data Collection Methods}

Grove et al. (2013) define data collection as the exact, systematic gathering of information related to the research purpose of the intended study. In this study, the data were collected by the researcher using semi-structured individual interviews, which lasted for 30 to 40 minutes, in accordance with an interview guide, until the data were saturated. Before collecting the data, the researcher asked a colleague to check the interview guide, looking for questions that might lead to biased data that the researcher might not have noticed. The researcher conducted the interviews himself. The participants' permission was requested to record all the conversations. The main questions posed during the interviews included the following: 
- What challenges do undergraduate nursing students face in the writing of the research proposal at UNAM?

- What recommendations would you make to address the challenges students are facing when writing their research proposals at UNAM?

\section{Data Analysis}

Thematic analysis was used to analyse the data as this is deemed the most reliable method used in qualitative research; it is fairly systematic and allows the researcher to organise the information into themes and subthemes (Leedy and Ormrod 2013). The transcribed interviews and narratives from the research notes were organised into codes, main themes and subthemes. An independent coder then verified the accuracy of the analysed data and held a meeting with the researcher to discuss and agree on the themes identified.

\section{Data Trustworthiness}

The trustworthiness of the entire study was assessed using the criteria proposed by Lincoln and Guba (1985), namely criteria relating to the credibility, transferability, dependability and confirmability of the study. Credibility focuses on whether the results accurately represent the underlying meaning of the data, is improved by prolonged engagement in the data collection process as well as by triangulation (Houser 2012), and is ensured through prolonged and varied engagement with the participants in the field. In this study the researcher used in-depth interviews, observations and field notes to ensure data triangulation. The data were subsequently analysed in depth by the researcher and an independent coder.

Lincoln, Lynham, and Guba (2011) describe "transferability" as the extent to which the findings of a study are confirmed by or applicable to a different group in a different setting (Rebar and Gersch 2015). In order to ensure the transferability of this study, a dense description of the research methodology and the participants' demographics has been provided, along with supporting verbatim quotes from the participants. Lincoln et al. (2011) refer to "dependability" as the means by which the research findings are consistent and sufficiently accurate to establish the trustworthiness of the study (Holloway and Wheeler 2010). Accordingly, the researcher collected data until data saturation was achieved, which was the point at which repeated and consistent findings were obtained from the in-depth interviews.

According to Lincoln et al. (2011), "confirmability" means that an audit or decision trail is necessary for readers to trace data to their sources. This was accomplished by establishing an audit procedure or audit trail, which was applied throughout the research process to ensure confirmability. In addition, the researcher documented the decisions made about the data collection and analysis process. Such documentation included field notes on the collected data and ideas developed during the analysis. Thus, confirmability was ensured through ongoing analysis as well as member checking by confirming the 
correctness of their responses with the participants themselves. Testing of the interview guide was conducted with three students who were not part of the study. The final themes and subthemes were identified after consensus had been reached during a meeting between the researcher and the independent coder.

\section{Ethical Considerations}

Before conducting the study, institutional approval was sought from the Health Research Ethics Committee of UNAM with reference number SoNREC 05/2020. Throughout the study, the researchers' conduct was guided by the following ethical principles: beneficence, non-malfeasance, confidentiality, privacy, anonymity, justice, informed consent and autonomy. The participants' data were accessible only to the researchers involved in the study. The participants were assured of privacy, anonymity and confidentiality as well as their right to terminate their participation in the study at any point without having to explain themselves or receive penalties for doing so.

Results

\section{Characteristics of the Study Participants}

The participants were all undergraduate Bachelor of Nursing Science (Clinical) (Honours) students. All the participants were under the age of 50 and were all unemployed. The characteristics of the study participants are given in table 1 .

Table 1: Characteristics of the participants

\begin{tabular}{|l|l|}
\hline Age & Total \\
\hline $18-30$ & 16 \\
$31-40$ & 3 \\
$41-50$ & 1 \\
$51-60$ & 0 \\
61 and above & 0 \\
\hline Gender & \\
\hline Male & 11 \\
Female & 9 \\
\hline Marital status & \\
\hline Single & 18 \\
Married & 2 \\
\hline
\end{tabular}

The themes that emerged from the data analysis are indicated in table 2 as follows: challenging individual experiences; academic and institutional factors such as the influence of the supervisor; and recommendations for improvement measures. 
Table 2: Themes and subthemes which emerged from the data analysis

\begin{tabular}{|l|l|}
\hline Themes & Subthemes \\
\hline $\begin{array}{l}\text { Challenging experiences } \\
\text { phen writing the research } \\
\text { proposal }\end{array}$ & $\begin{array}{l}\text { Shortage of library resources } \\
\text { Non-existent teaching on library information literacy } \\
\text { Personal time management } \\
\text { Lack of knowledge on how to write } \\
\text { Finding topics for approval } \\
\text { Practical as the overriding factor } \\
\text { Too many tests restrict time for research } \\
\text { Academic writing is done in the first year } \\
\text { Ministry of Health and Social Services topics challenging } \\
\text { Long wait for research approval }\end{array}$ \\
\hline $\begin{array}{l}\text { Influence of the } \\
\text { supervisor }\end{array}$ & $\begin{array}{l}\text { Detrimental interrelationship } \\
\text { Feedback from supervisors unhelpful } \\
\text { No encouragement from supervisors }\end{array}$ \\
\hline $\begin{array}{l}\text { Recommendations for } \\
\text { improvement }\end{array}$ & $\begin{array}{l}\text { Proper guidance will lead to shorter time spent on research } \\
\text { More people should be employed at the Ministry of Health and } \\
\text { Social Services (MoHSS) research unit } \\
\text { Teaching on library information literacy } \\
\text { Make data available for those not at a hostel } \\
\text { Improved interrelationship between students and supervisors } \\
\text { Academic writing to be introduced in the third year }\end{array}$ \\
\hline
\end{tabular}

A detailed description of the themes and categories in this study is given below.

\section{Theme 1: Challenging Experiences}

This theme describes the types of challenges participants experienced when writing their research proposals. Subthemes that fall under this theme are: the shortage of library resources; non-existent teaching on library information literacy and the search for information; personal time management; lack of knowledge on how to write; finding topics for approval; practicals as an overriding factor; too many tests that restrict time for research; academic writing done only in the first year; and Ministry of Health and Social Services' topics challenging. The verbatim excerpts below from 20 of the interviews give insight into challenges experienced.

\section{Shortage of Library Resources}

Participants described the shortage of library resources leading to a lack of extensive literature as a setback that hindered them from writing their research.

I have realised that our library does not have a lot of books or might as well say that we are not exposed to a lot of books in our library and due to that it is very difficult to do my research because I do not even know where to get my literature (P1). 


\section{Ashipala, Livingi}

The findings of this study are in agreement with a study done by Kikula and Qorro (2007) on the challenges faced by undergraduate students when writing research proposals in Tanzania. The study found that students had inadequate literature, resulting in their being unable to attain a certain level of focus in their research writing activities. This lack of literature is unfortunate and is due to a lack of resources.

\section{Non-existent Teaching on Library Information Literacy}

Participants mentioned that there was insufficient information to assist them in going online to search for crucial information pertaining to their research topics. Participants mentioned being unable to obtain the information required for their research and were of the opinion that it was important to be taught library information literacy to guide them in searching for information on the internet. One participant had this to say:

We were never taught on how to go online and search for information (P18).

Accordingly, the participants felt themselves to be in an invidious position because they did not have adequate library resources, nor did they know how to search for information. This is in line with a study done by Shrestha (2008), who found that university libraries should have a thorough knowledge of users' needs. Without knowing the information needs of their users it is difficult to provide them with effective and efficient services.

\section{Personal Time Management}

Participants raised the issue of not having enough time available since they had to find a balance between their academic and personal lives, which they found quite challenging.

I feel like time was not on my side because I had to do things scheduled for own personal time and having to balance it with academics was very challenging (P19).

The study revealed that participants lacked personal time management, having to balance time spent on practicals and classes with their personal and academic lives. These findings are aligned with those of Manchishi, Ndhlovu and Mwanza (2015), who state that one of the major challenges facing students in their proposal writing is a lack of time.

There were other important things do to do and not only proposal writing and I believe that that actually delayed me from finishing my proposal (P16).

According to Manchishi et al. (2015), distance students are not accorded sufficient time or exposure to contact sessions that discuss research, owing to the limited time spent at residential tutorials or on campus. Despite the fact that it is the students' responsibility to remain committed to their academic work, research proposal writing also requires adequate exposure and sufficient guidance. 


\section{Lack of Knowledge on how to Write}

One of the factors participants mentioned pertaining to the obstacles that might have contributed to the problems experienced when writing a research proposal, was a lack of knowledge on how to write, as well as a lack of knowledge of the concepts involved. This is what one participant had to say:

I am struggling to write because the academic knowledge is not really there; we were only taught academic writing only in the first year (P3).

Manchishi et al. (2015) established that postgraduate distance students in Zimbabwe faced a number of challenges in their proposal and thesis writing. Significantly, these included the assumption that students at the postgraduate level possess adequate proposal writing skills, when in actual fact they do not.

This is what one participant had to say in this regard:

Sometimes we as students we lack the knowledge on how to write because we do not understand research (P18).

It emerged from this study that students lacked knowledge of research and this was hindering them in writing their proposal. Kombo and Tromp (2011) identified problems with titles being too wide, too wordy and lacking consistency with the text. Another challenge found was the poorly written background to the study, with no difference between the background and the literature review. In addition, while studies were quoted, how they fitted into the background section was not explained.

\section{Finding Topics for Approval}

Participants raised their frustrations concerning the difficulty they faced when it came to choosing research topics and mentioned that they found this very difficult:

I was struggling to get a topic of good quality because I had no knowledge of what to look for (P2).

When you choose a certain topic that you want to focus on, you will just be told by your supervisor that it has been done already by another student (P7).

The study found that students experience difficulties in finding topics for approval. These findings are aligned with those of a study done by Manchishi et al. (2015), which found that students' mistakes in writing proposals include broad and unclear topics, failure to state the problem, failure to identify a gap in the literature, the use of incorrect methodology, misunderstanding research terminology, incorrect referencing style and plagiarism. Another study by Kombo and Tromp (2011) identified problems as titles being too wide, too wordy and lacking consistency with the text. 


\section{Ashipala, Livingi}

\section{Practicals as an Overriding Factor}

Practical work was seen as one of the factors that prevented participants from focusing on their proposal writing because such practicals tend to exhaust them. This is what participants had to say:

You know with practical when you come back you are tired and this stops you from working on your research proposal writing (P14).

Nursing is a very challenging course because we are always having practical and at the same time you are required to do your research and this is very hard for me to complete my proposal because I am always exhausted (P20).

It also emerged from the study that students could not focus on their proposal writing because of the exhaustion resulting from preparing for procedures done during clinical rotations. This finding aligns with that of Kim et al. (2014). Emotional exhaustion is the core component of academic burnout resulting from long-time academic stress. Shin et al. (2011) state that, in a university context, students who experience exhaustion feel physically and emotionally fatigued and drained by the academic demands made on them to succeed.

\section{Too many Tests Restrict Time for Research}

Participants claimed that being overloaded with tests meant that they did not have enough time to focus on their research proposal.

Sometimes we have a lot of tests, sometimes we write three to four tests in a week, and like that it causes a lot of pressure because you have to study and get good grades, this limits my time to do my research (P13).

They are always giving us tests to write and I always spend most of our time studying and I really do not get that time to do my research $(\mathrm{P} 2)$.

The study found that students experienced work overload because they write many tests, thus they will be studying for these tests rather than focusing on their research. Students and distance students appear to have limited time, an issue that has to be adequately addressed (Komba 2016). As a result of the notable challenges and the demanding nature of research proposal writing, Murray (2012, suggests holding writing clinics within departments to help students acquire the writing skills that are essential in writing research proposals.

\section{Academic Writing Done in the First Year}

Participants expressed their concerns about only being taught academic writing in the first year, which resulted in their not obtaining full knowledge of academic writing:

We were only taught academic writing in [the] first year (P6). 


\section{Ashipala, Livingi}

I do not know how to write academically since it was done only in my first year (P1).

I lack the skills of academic writing since it is not even taught anymore (P11).

Participants in this study reported that academic writing skills were only covered during their first year of study and this created a burden for them during thesis writing. Kikula and Qorro (2007) conducted a study in Tanzania on the challenges faced by undergraduate students when writing research proposals and found that among 783 research proposals submitted, the titles were either too broad or lacked focus, the introductions lacked clarity and focus, the statement of problems lacked a problem statement and lacked clarity and focus, as well as not covering irrelevant issues.

\section{Ministry of Health and Social Services Topics Challenging}

Participants explained that topics that needed to be reviewed and approved by the Ministry of Health and Social Services often took too long to be approved.

Topics which are for the Ministry are taking long to be approved, I think we started with our research around March and April but up until now we are almost at the end of the year and our topics are still not approved (P3).

Our research proposals are just being piled up waiting for approval because there are many institutions as well (P2).

The participants in the current study indicated that proposals take a long time to be approved by the MoHSS. In their study, Sikongo, Ashipala and Pretorius (2020) also reported that the approval of research proposals is delayed by the Ministry.

\section{Theme 2: Influence of the Supervisor}

In this theme, participants described the influence of their supervisors as affecting them in a negative way because support from their supervisors was lacking and there was no positive engagement with them. Subthemes under this theme include detrimental interrelationships, unhelpful feedback from supervisors, and no encouragement from supervisors.

\section{Detrimental Interrelationships}

Participants felt that they did not have a good relationship with their supervisors and this resulted in a communication barrier.

The relationship between me and my supervisor has not been good, because for instance my supervisor can give me a task to draft my proposal without a good explanation of what is actually expected from me (P12).

I had a bad supervisor and our relationship was not good, she never made time for me (P6). 
A lack of engagement between participants and their supervisors resulted in supervisors withholding information that students needed:

I did not have a good supervisor; there was no positive engagement between us. Therefore, I even had to change supervisors because I was not getting the right help/information (P3).

It is reported in this study that participants generally did not have a good relationship with their supervisors and this led to a lack of communication between them. The findings of this study are aligned with those of Lumadi (2008), who found that some students complain about not being able to contact supervisors and having to wait a long time to get feedback. Another study done by De Vos (2015) suggests that some of the challenges associated with the quality of proposal writing are related to misunderstandings between students and their supervisors.

\section{Feedback from Supervisors unhelpful}

Participants complained that they were not receiving positive feedback from their supervisors and that they found the feedback unhelpful and not useful:

Sometimes we are told to look for information when we submit our proposals for review/feedback because it is not of good quality but now as a student, I don't even know what information to look for (P10).

My supervisor was not really being helpful when it came to feedback because he would send me things that I needed to work on that I couldn't even understand (P7).

When you ask a supervisor to explain something he/she will be like "I also do not know" or perhaps say that it is not my problem (P11).

Manchishi et al. (2015) indicate that students received erratic feedback from their supervisors, which leads to students developing poor attitudes towards research proposal writing. In addition, a study conducted by Sikongo et al. (2020), exploring the experiences of postgraduate nursing students involved in postgraduate nursing diploma coursework and research at UNAM, found that a rigid relationship with some of the lecturers affected students' work negatively.

\section{No Encouragement from Supervisors}

Participants expressed concerns about the amount of motivation received from their supervisors to help them through their research and push them to work harder. This is what one participant had to say:

We are not really being motivated by our supervisors; we are just being told to do our work (P7). 
The current study discovered that motivation and encouragement from research supervisors determine the success of research students when doing their undergraduate programmes. This finding is in line with that of Tahir et al. (2012), who determined that effective supervision is the most important attribute of supervisors. Supervisors should be friendly, approachable and flexible, knowledgeable and resourceful, and should encourage students to work and plan independently.

There was no motivation from my supervisor; there were times I felt like not doing the research anymore (P9).

De Vos (2015) states that the quality of research proposal writing reflects the level of supervision. De Vos (2015) points out that the challenges students face in writing proposals are often made more difficult by the fact that supervisors have tacit knowledge about the features of and approaches to proposal writing that they do not communicate to students. This may result in a strong sense of isolation.

\section{Theme 3: Recommendations for Improvement}

In this theme, participants came up with possible solutions that could be implemented to help improve this area of research at UNAM. Subthemes include the following: proper guidance will lead to shorter time spent on research; more people should be employed at the MoHSS Research Unit; and academic writing to be introduced in the third year.

\section{Proper Guidance will Lead to shorter Time Spent on Research}

Participants suggested obtaining help from their supervisors. Such help included providing students with proper guidance so that they do not spend so much time struggling when it comes to drafting their research proposals.

Supervisors need to put in more effort so they guide us properly and give us correct information (P15).

Our research lecturer should at least allow us all to have research topics so that when he is teaching, we are able to move and we will be guided properly on how to write our proposals (P13).

Students felt that they were being given no direction or guidance. When being taught about proposal writing, some students still had not identified research topics of interest. The findings of this study are in agreement with those of Mapolisa and Mafa (2012), who also described that students in their study reported too little direction, too little practical help given, no interests in topics, and that no interest in students was received from their supervisors. 


\section{More People should be Employed at the MoHSS Research Unit}

Participants suggested that more people should be employed by the MoHSS to focus on reviewing the research proposals, so that students do not have to wait such a long time to have their topics approved.

I was suggesting that they employ more people in those offices so that our proposals don't just queue up (P15).

The participants expressed overwhelming concern about the need to improve the research proposal process. In their study, Sikongo et al. (2020) also suggested that more people should be recruited for the MoHSS research unit to expedite the process of research approval.

\section{Academic Writing in the Third Year}

Participants suggested that there was indeed a need for academic writing to be introduced in the third year. They felt that this was important because the drafting of the research proposal required academic writing skills.

I feel like academic writing should be introduced in [the] third year because writing of the proposal will now be way too easy (P6).

Academic writing should be done in [the] third year as well since we only did it in [the] first year (P8).

We should be taught on how to write academically now that we are doing research (P11).

In the current study, most participants suggested that academic writing should be introduced in their third year of study and not only their first year of study. A study by Altınmakas and Bayyurt (2019) on factors influencing undergraduate students' academic writing practices in Turkey, found that attaining the desired level of competence and fluency in academic writing is important for students majoring in English-medium undergraduate programmes, because their academic achievements are determined by the texts they produce in English.

\section{Limitations of the Study}

The limitations of this study relate to the difficulty in finding literature related to the experiences of undergraduate students in the writing of research proposals. As this study focused on the challenges experienced by undergraduate nursing students when writing research proposals in the north-eastern part of Namibia, their perspectives on this subject may differ from nursing students who are enrolled at other campuses and institutions. This limits generalisation to students who are registered at other campuses because they might not have encountered similar challenges. As a result, the findings of the current study cannot be generalised to other campuses. 


\section{Recommendations}

Based on the findings of this study, participants advanced the following recommendations to the School of Nursing:

- Research supervisors should provide students with proper guidance, thus enabling students to spend less time on writing research proposals.

- Improved relationships between students and supervisors should be fostered because they are very important in promoting communication between them, allowing them to work together effectively.

- A platform should be created for providing library information literacy, where students are exposed in different ways to searching for information on the internet.

- Students should be provided with reliable internet connectivity. This is seen as essential, especially during the period of research proposal writing, because some students do not live on campus and many lack the data needed to use the internet for research.

- Owing to students' lack of skills, academic writing should be introduced in the third year, as that is the year in which the research proposal is written.

- More people should be employed by the MoHSS office dealing with the issue of research, so that topics may be approved faster.

\section{Conclusion}

The findings of this study have shown that writing a proposal in preparation for conducting research is often overwhelming for undergraduate nursing students, who are confronted with this task for the first time, and students react differently to the challenge. The challenges identified in this study were a lack of proper guidance from supervisors, a lack of academic writing skills, a lack of library information literacy, poor relationships between students and supervisors, and long waits for research approval. It was also revealed that clinical practice is one of the overriding factors affecting the completion of the proposal. Therefore, there is a need for intervention strategies to address the challenges that students face when writing their research proposals. Finally, the findings show that all undergraduate nursing students should take ownership of their studies, especially when writing their research proposals and, additionally, lecturers need to be more involved in assisting students with academic writing.

\section{Acknowledgements}

The researchers thank all respondents who took the time to participate in this study, without which this study would not have been possible. The researchers declare that they had no financial or personal relationship(s) which may have influenced them inappropriately in the writing of this article. Both researchers were involved in the 


\section{Ashipala, Livingi}

conceptualisation, literature review, data collection, data analysis and writing of the manuscript. This research received no specific grant from any funding agency in the public, commercial and/or not-for-profit sectors.

\section{References}

Altınmakas, D., and Y. Bayyurt. 2019. “An Exploratory Study on Factors Influencing Undergraduate Students' Academic Writing Practices in Turkey.” Journal of English for Academic Purposes 37. https://doi.org/10.1016/j.jeap.2018.11.006.

Anderson, L. W., and D. R. Krathwohl. 2001. A Taxonomy for Learning, Teaching, and Assessing: A Revision of Bloom's Taxonomy of Educational Objectives. New York: Longman.

Asogwa, V. C., A. D. Wombo, and C. U. Ugwuoke. 2014. "Challenges and Coping Strategies Adopted by Postgraduate Students of Agricultural Education in Thesis Writing in Nigerian Universities." American Journal of Operations Research 4: 311-318. http://dx.doi.org/10.4236/ajor.2014.45030.

Bitchener, J., and H. Basturkmen 2006. "Perceptions of the Difficulties of Postgraduate L2 Thesis Students Writing the Discussion Section." Journal of English for Academic Purposes 5 (1): 4-18. https://doi.org/10.1016/j.jeap.2005.10.002.

Botten, E. L. 2012. "Writing Your Dissertation: Where to Start." British Journal of Nursing 21 (22). https://doi.org/10.12968/bjon.2012.21.22.1323.

Brink, H., C. van Der Walt, and G. van Rensburg. 2018. Fundamentals of Research Methodology for Health Care.

De Vos, C. 2015. "The Kata Kolok Pointing System: Morphemization and Syntactic Integration." Topics in Cognitive Science 7 (1): 150-168. https://doi.org/10.1111/tops.12124.

Govender, K. K., and S. Ramroop. 2013. "The Relationship among the Postgraduate Research Climate, Role Clarity and Research Service Quality." South African Journal of Higher Education 27 (1): 60-75.

Grove, S. K., N. Burns and R. Gray. 2013. The Practice of Nursing Research: Appraisal, Synthesis, and Generation of Evidence, 7th edition. St Louis, MO: Elsevier.

Hartley, J., and S. Jory. 2015. "Lifting the Veil on the Viva: The Experience of Psychology PhD Candidates in the UK." Psychology Teaching Review 9 (2): 79-90.

Holloway, I., and S. Wheeler. 2010. Qualitative Research in Nursing and Health Care. London: Wiley-Blackwell.

Houser, J. 2012. Nursing Research, Reading, Using and Creating Evidence, 2nd edition. Burlington MA: Jones and Bartlett Learning. 
Kikula, I. S., and M. A. Qorro. 2007. Common Mistakes and Problems in Research Proposal Writing: An Assessment of Proposals for Research Grants Submitted to Research on Poverty Alleviation REPOA (Tanzania). Research on Poverty Alleviation.

Kim, B., M. Lee, K. Kim, H. Choi, and S. M. Lee. 2014. "Longitudinal Analysis of Academic Burnout in Korean Middle School Students.” Stress and Health 31 (4): 281-289.

Komba, S. C. 2016. "Challenges of Writing Theses and Dissertations Among Postgraduate Students in Tanzanian Higher Learning Institutions." International Journal of Research Studies in Education 5 (3): 71-80.

Kombo, K. D., and L. A. Tromp. 2011. Proposal Thesis Writing. Kerala, India: Don Bosco Printers.

Leedy, P., and J. Ormrod. 2013. Practical Research: Planning and Design, 10th edition. New York: Pearson.

Lessing, A. C., and S. Schulze. 2002. "Postgraduate Supervision and Academic Support: Students' Perceptions.” Journal of Higher Education 16 (2): 139-149. http://dx.doi.org/10.4314/sajhe.v16i2.2525.

Lincoln, Y. S., and E. G. Guba. 1985. Naturalistic Inquiry. Thousand Oaks, CA: Sage Publications.

Lincoln, Y. S., S. A. Lynham, and E. G. Guba. 2011. "Paradigmatic Controversies, Contradictions, and Emerging Confluences Revisited." In The Sage Handbook of Qualitative Research, edited by N. K. Denzin and Y. S. Lincoln, 4th edition, 97-128. Thousand Oaks, CA: Sage Publications.

Lumadi, M. W. 2008. "The Pedagogy of Postgraduate Research Supervision and its Complexities." College Teaching Methods and Styles Journal (CTMS) 4 (11): 25-32. https://doi.org/10.19030/ctms.v4i11.5577.

Mafa, O., and T. Mapolisa. 2011. "Supervisors' Experiences in Supervising Postgraduate Education Students' Dissertations and Theses at the Zimbabwe Open University (ZOU).” International Journal of Asian Social Science 2 (10): 1685-1697.

Manchishi, P. C., D. Ndhlovu, and D. S. Mwanza. 2015. "Common Mistakes Committed and Challenges Faced in Research Proposal Writing by University of Zambia Postgraduate Students." International Journal of Humanities Social Sciences and Education (IJHSSE) 2 (3): 126-138.

Mapolisa, T., and O. Mafa. 2012. "Challenges Being Experienced by Undergraduate Students Conducting Research in Open and Distance Learning." International Journal of Asian and Social Science 2 (10): 1672-1684. 


\section{Ashipala, Livingi}

Maree, J. G. 2016. "Advancing Career Counselling Research and Practice Using a Novel Quantitative + Qualitative Approach to Elicit Client's Advice from Within." South Africa Journal of Higher Education 32 (4): 149-170. http://dx.doi.org/10.20853/32-4-2558.

Murray, R. 2012. How to Write a Thesis. Buckingham, UK: Open University Press.

Namibia Qualification Authority (NQA). 2014. Draft Policy Statement: Naming of NQF Qualifications. Accessed April 23, 2021. http://www.namqa.org/files/downloads/674_Qualification\%20names.pdf.

Nkomo, M. 2013. “Initiating Debate: South Africa’s Achilles Heel and Phoenixian Possibilities: Reflections on Structured Underdevelopment and Transformation Challenges." South African Journal of Higher Education 27 (1): 5-23.

Oxford Dictionary. 2019. s.v.v. "undergraduate students"; "challenges"; "postgraduate nursing student"; university." http://dictionary.cambridge.org/dictionary/english/.

Paul, T. P. 2015. How to Write a Psychology Research Proposal. Accessed January 10, 2020. https://notendur.hi.is/th/MSritgerdir/How\%20to\%20Write\%20a\%20Research\%20Proposal .pdf.

Polit, D. F., and C. T. Beck. 2012. "Integration of Qualitative and Quantitative Designs.” In Nursing Research: Principles and Methods, edited by D. F. Polit, and C. T. Beck, 273288. Lippincott Williams and Wilkins.

Rebar, C. R., and C. J. Gersch. 2015. Understanding Research for Evidence-based Practice, 4th edition. Philadelphia, PA: Wolters Kluwer Health, Lippincott, Williams and Wilkins.

Shin, H., B. Kim, M. Lee, H. Noh, K. Kim, and S. M. Lee. 2011. “A Short-term Longitudinal Study of Mental Health and Academic Burnout among Middle School Students." The Korean Journal of School Psychology 8 (2): 133-152. https://doi.org//10.16983/kjsp.8.2.133.

Shrestha, N. 2008. "A Study on Student's Use of Library Resources and Self-efficacy." Master's Degree Thesis in Library and Information Science, Tribhuvan University, Kirtipul, Nepal.

Sikongo, L., D. O. Ashipala, and L. Pretorius. 2020. "Experiences of Postgraduate Nursing Students at the University of Namibia." African Journal of Nursing and Midwifery 22. https://doi.org/10.25159/2520-5293/6622.

Tahir, I. M., N. A. Ghani, E. Suhaimi, E. S. E. Atek, and Z. Manaf. 2012. "Effective Supervision from Research Students' Perspective." International Journal of Education 4. https://doi.org/10.5296/ije.v4i2.1531.

Taylor, S., and N. Beasley. 2015. A Handbook for Doctoral Supervision. London: Routledge. 


\section{Ashipala, Livingi}

Wang, T., and L. Y. Li. 2008. “Understanding International Postgraduate Research Students' Challenges and Pedagogical Needs in Thesis Writing." International Journal of Pedagogies and Learning 4 (3): 88-96. http://dx.doi.org/10.5172/ijpl.4.3.8. 